\title{
Elephant crop-raiding and human-elephant conflict in Cambodia: crop selection and seasonal timings of raids
}

\author{
C. Elizabeth Webier, Tuy Sereivathana, Matthen P. Maltib \\ and PHYLIS C. LEE
}

\begin{abstract}
Elephants are threatened globally by habitat loss, poaching and accelerating levels of human-elephant conflict. For Elephas maximus in Cambodia, crop raiding underlies this conflict. Understanding the timing of raids and selection of crops can help design locally appropriate mitigation and management strategies. This study, using a 4-year database of events, investigated the most frequently raided crops and patterns of raids, over time and seasons and by location. Damage frequency varied significantly by crop, with rice, banana, cassava, sugar cane and papaya most frequently raided. Considering raid events per unit crop area, banana, sugar cane and pineapple were raided more than would be expected based on their availability. There were differences in both crop-raiding events and crop-damage frequencies over study years and there was a peak raiding season in October-December. Nationally, significant differences were found among provinces but not between years. Rates of damage decreased after mitigation strategies such as observation towers, deterrents and fences were implemented. We suggest further mechanisms to improve human-elephant conflict monitoring in relation to crop choice and availability.
\end{abstract}

Keywords Asian elephants, Cambodia, crop-raiding management, crop selection, Elephas maximus, human-elephant conflict

\section{Introduction}

- lephant Elephas maximus populations across Asia are Ethreatened by poaching, illegal capture and trade (Menon et al., 1997; Goldthorpe et al., 2003; Sukumar, 2006), habitat fragmentation and conversion, and by human-elephant conflict (Leimgruber et al., 2003; Hedges et al., 2005). Asian elephants now survive in only $5 \%$ of their

C. Elizabeth Webber* (Corresponding author) and Phyllis C. Lee Behaviour \& Evolution Research Group, Department of Psychology, University of Stirling, Stirling, FK9 4LA, UK. E-mail cw35@stir.ac.uk

Tuy Sereivathana and Matthew P. Maltby Cambodian Elephant Conservation Group, Fauna \& Flora International, Phnom Penh, Cambodia

*Also at: Institute of Zoology, Zoological Society of London, Regent's Park, London, UK, and The Royal Veterinary College, University of London, London, UK

Received 13 July 2009. Revision requested 18 January 2010.

Accepted 6 February 2010. historical range (Sukumar, 2003, 2006), with an estimated population of 38,000-52,000 (Kemf \& Santiapillai, 2000; Blake \& Hedges, 2004; Sukumar, 2006). Populations in Laos, Thailand, Vietnam and Cambodia are thought to be 500-1,000, 2,500-3,200, 70-150 and 250-600, respectively (Sukumar, 2003). However, these figures may be little more than guesses (Duckworth \& Hedges, 1998; Blake \& Hedges, 2004). The Vietnam War (1964-1973) destroyed large areas of forest in Cambodia, Vietnam and Laos (Santiapillai \& Jackson, 1990; Gilmour et al., 2000). Economic growth and expanding populations have led to the growth of agriculture and widespread changes in land use in Cambodia and elsewhere in Asia. For Cambodia's elephants weak governance and low technical capacity for implementing forest protection further threaten habitat availability and connectivity. Threats include land grabbing and speculation by the ruling elite, mining and agricultural concessions granted with little or no environmental impact assessment, planned large-scale hydroelectric dam projects, and improvements in infrastructure such as roads (WildAid Cambodia, 2003).

Although the number of elephants in Cambodia is considerably fewer than those in India, Cambodia's area of potential elephant habitat is $>40,000 \mathrm{~km}^{2}$ (Dany et al., 2001; Sukumar, 2003) and, consequently, viable populations could be maintained in suitable areas. Anthropogenic activities, however, which compromise elephant habitats, also force elephants into direct contact with human subsistence activities and result in human-elephant conflict (Hoare, 1999; Sukumar, 2006). Continual conflicts with elephants cause resentment and retribution killings of elephants, and can inhibit conservation efforts (Karidozo \& Osborn, 2005; Sitati et al., 2005). In Vietnam, where there are almost no elephants, small herds involved in conflicts have been eradicated (Heffernan \& Cuong, 2004). In most conflict contexts with humans, elephants simply cannot win. Mitigation strategies to reduce or contain crop raiding, coupled with the restoration of tolerance of wildlife by communities (O'Connell-Rodwell et al., 2000; Remis \& Hardin, 2009) are imperative for the future of elephants.

Understanding when, how and which crops are taken by elephants in relation to planting and harvesting cycles facilitates the prediction of crop vulnerability by managers, who can then decide which mitigation strategies will be useful for specific crops, and where and when to apply these strategies to maximize their effectiveness. In the study 
described here we investigate records of elephant crop raiding in Cambodia on a province-by-province basis. Examining crop-raiding behaviour at a local level can help develop targeted monitoring and effective mitigation strategies and concentrate limited resources where they will be most efficient (Sitati et al., 2005).

The first major question is which crops are taken and the second is when does raiding occur? These questions are linked in that crop raiding tends to be seasonal and selective but whether seasonal patterns depend on peaks and troughs of availabilities in natural foods or cycles of planted crops is poorly understood. Seasonal raiding patterns have been associated with the harvesting of specific crops (Sukumar, 1989, 1990), attraction to high nutrient quality and palatability, along with reduced chemical defences and high water retention of cultivated crops in comparison to wild vegetation (Sukumar, 1989, 1990; Chiyo et al., 2005), seasonal reduction in wild grass availability and quality (Osborn, 2004), and proximity of cultivation to protected area boundaries (Naughton-Treves et al., 1999).

Elephants often raid crops nocturnally and may consume or trample a variety of crops, including cereals, fruits, vegetables, sugar cane and palms (Sukumar, 1989). Male elephants are the most frequent raiders, either singly or in small groups, and engage in risk-taking behaviour to capitalize on gaining condition prior to sexually active musth periods (Sukumar, 1989; Hoare, 1999; Graham et al., 2009). However when females raid in larger groups they can cause significant economic damage to subsistence (Sitati \& Walpole, 2006) as well as commercial agriculture (Hoare, 1999; Sukumar, 2006). We used the Cambodian Elephant Conservation Group's (CECG) nationwide database of cropraiding events for 2003-2008 to investigate trends in elephant crop raiding. Such an analysis could enable targeted mitigation and management strategies at human-elephant conflict hotspots. The aims of this retrospective study were to investigate crop-raiding trends by analysing: (1) Which crops were raided most often? (2) Were there geographical patterns in frequency of crop raiding over time? (3) Were there seasonal variations in crop-raiding frequencies and location?

We also make suggestions to improve data collection and therefore the value and significance of future studies of elephant crop raiding. Continued and effective monitoring is of particular importance if Cambodia's elephant and human populations both expand as predicted, bringing a prospective increase in human-elephant conflict (WildAid Cambodia, 2003).

\section{Study area}

In $2005<60 \%$ of Cambodia's land was forested (FAO, 2009b). Elephant habitats are contiguous across international boundaries, and Cambodia's elephants occur mainly in the Cardamom Mountains and south-west Cambodia (encompassing the provinces of Koh Kong, Kampong Speu, Kampot, Preah Sihanouk, Pursat and Battambang; Dany et al., 2001; Sukumar, 2006) and in forested areas of Mondulkiri in the east. There is one small group in a lowland dry evergreen forest that includes parts of the provinces of Kratie, Stung Treng, Kampong Thom and Preah Vihear. Multiple small populations also occur in the north-east of Ratanakiri, bordering Laos and Vietnam, and near the Laos border in Preah Vihear (Dany et al., 2001; Fig. 1).

Total annual rainfall in Cambodia is generally 1,00o$1,500 \mathrm{~mm}, 80 \%$ of which falls in the monsoon season (MayNovember), and is heaviest in the south-east mountainous areas (Ross, 1987; Vance et al., 2004). In $200520.4 \%$ of Cambodia's land was arable (CIA, 2008) but conversion of forests to crops is occurring rapidly.

Rice Oryza sativa is Cambodia's main agricultural crop, with the major harvest of the monsoon-season crop yielding $85 \%$ of annual production. Planted in late May to July after the soil is softened by the first monsoon rains, shoots are then transplanted in late June to September and harvested in December. A secondary dry season crop with a shorter growth period is planted in November in areas where monsoon rains have been trapped or retained, and this crop is harvested in January-February (Ross, 1987; Farquharson et al., 2006).

\section{Methods}

The data analysed here derive from the CECG programme of monitoring crop raiding (a collaboration of Fauna \& Flora International with the Royal Government of Cambodia's Department of Nature Conservation \& Protection and Forestry Administration). The CECG project is concerned with developing and promoting human-elephant conflict mitigation strategies and raising local awareness of elephant conservation issues by actions such as encouraging farmers to grow chilli Capsicum annuum along the forest boundary to act as an elephant-resistant boundary and as a crop, the use of solar-powered electric fences and noise deterrents such as carbide explosions, the olfactory deterrent of chilli grease spread on ropes, scarecrow-type techniques using perfumed stuffed hammocks hung across elephant paths, watch towers and by supporting engagement between neighbouring communities. The CECG shares knowledge of optimal cultivation techniques, including intercropping two species, such as ginger Zingiber officinale and chilli, and damming water for irrigation in the dry season to help farmers improve yields using less water, land and labour. The aim is that less forest will be cleared and therefore encroachment into elephant habitats will be reduced. Alternative livelihoods are also supported by the CECG, to encourage diversity and hence a greater security of livelihood.

The CECG project endeavoured to have broad national coverage, via local liaison, for collection of evidence from 


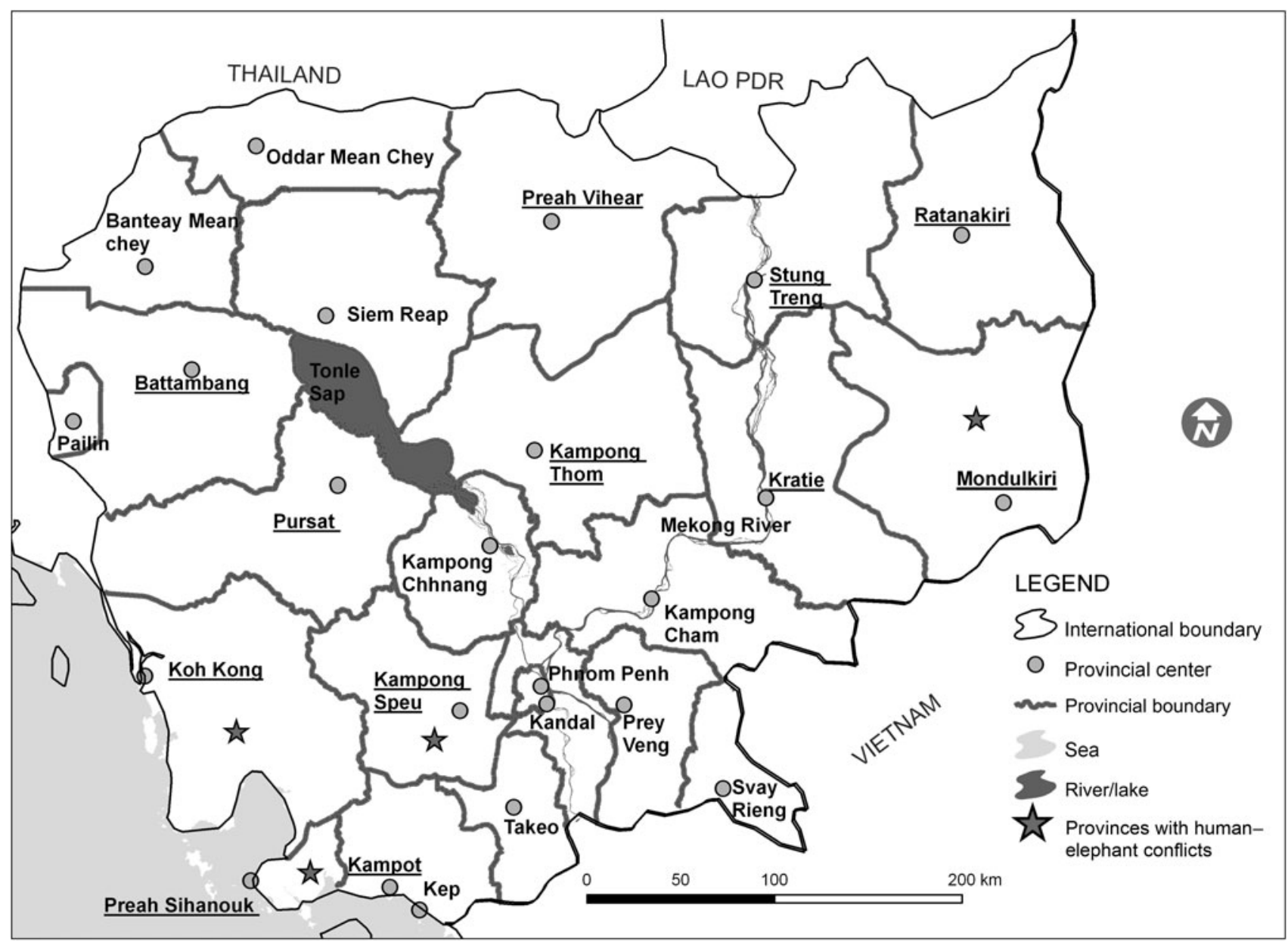

FIG. 1 Cambodia, with stars denoting provinces in which crop-raiding occurred. Underlined province names indicate those with major elephant populations.

every elephant crop-raiding incident (Table 1). Trained CECG field teams aimed to respond within 24 hours to conflict incidents. Complainants were interviewed and details of the conflict recorded, including complainant's identity, location (obtained with a global positioning system), the crop damaged, rangers' estimates of size of area damaged in square metres or by crop structure (e.g. tree or clump of trees) and any reports of damage to property or injury to people. The project aimed to ensure that the same types of data, and of the same quality, were collected by all rangers from year to year; this has yet to be formally assessed. In addition, CECG rangers recorded direct or indirect observations of elephants by villagers at any time, not necessarily associated with crop raids. All data were stored in a database in Phnom Penh and updated monthly.

The total number of times that each crop was damaged in raids was calculated per year and overall from August 2003 to April 2008 inclusive. An annual crop damage index, raids per ha harvested, was calculated from the frequency that a crop was damaged divided by the total annual area harvested of the seven crops for which data were available

TABLE 1 Information recorded for each elephant crop-raiding incident by the CECG.

\begin{tabular}{llllll}
\hline Complainant & Elephant & Dates & Location & Crop damaged & Property damaged \\
\hline Assigned ID number & Assigned ID & Conflict date & GPS coordinates & Crop type & Property type \\
Name & (if known) & Complaint date & Province & Quality \& & Status \\
Attitude to incident & Name (if known) & & District & maturity status & Property unit size \\
Property size & & Commune & Crop unit size & Total size \\
& & & Village & Total size & Size damaged \\
& & & Size damaged & \\
\hline
\end{tabular}

${ }^{\star}$ Unit measured as area, number of trees or number of clumps, depending on crop type 
(FAO, 2009a). Frequency of damage to each crop and the number of raiding events (which may include damage to several different crops) were investigated separately for each province, although regional harvested areas were not available. Monthly crop damage frequencies were related to average monthly rainfall (Pearce \& Smith, 1993) to assess temporal crop selection overall and by province. Mean monthly frequency of damage to rice was assessed in relation to Cambodia's rice-growing seasons. Statistical analysis was carried out using SPSS v. 16.o (SPSS, Chicago, USA). Comparisons between frequencies of crop damage were on a pairwise basis, assuming a Poisson distribution (with $z>1.96$, two tailed). Relationships between frequencies of crop damage and annual harvested area of each crop were determined with correlations. Non-parametric tests (Friedman's analysis of variance and Spearman's $r_{\mathrm{s}}$ ) were used for non-normally distributed data. When data could be normalized by $\log _{10}$ transformations, parametric tests (ANOVA, Pearson's $r$ ) were used. Significance was at $\mathrm{P}<0.05$, and all tests were two tailed.

\section{Results}

Crop-raiding incidents involved 21 crops (Table 2). Elephants raided rice most frequently and other highly raided crops included bananas, cassava, sugar cane and papaya. Elephants also damaged a variety of other available crops at lower frequencies. For the seven crops for which the total annual harvested area is available (FAO, 2009a), there is a significant, positive linear relationship between frequency of raiding events and area harvested $(r=0.513, \mathrm{n}=28$, $\mathrm{P}=0.005)$. The area of crop available varied from 2,542,300 ha (rice) to 1,600 ha (pineapple) and frequencies of raids on these crops occurred from o to 70 times per year. Banana, sugar cane and pineapple had the highest damage indices, and rice and maize the lowest (Fig. 2).

Raiding events were reported in the south-west provinces of Kampong Speu, Koh Kong and Preah Sihanouk and in the eastern province of Mondulkiri (Fig. 3). Total raids differed significantly among provinces, irrespective of crop type (Friedman $\chi^{2}=11.22, \mathrm{df}=3,5, \mathrm{P}=0.011$ ), and the province-specific patterns were similar across the years of the study.

While there were some differences in raided crop types among provinces, these were not significant (Friedman $\left.\chi^{2}=9.16, \mathrm{df}=3,5, \mathrm{P}=0.103\right)$. In Mondulkiri the crop raided most was rice, whereas in Kampong Speu banana was raided slightly more often than rice. Papaya was also raided more often than sugar cane or cassava in Kampong Speu. In Koh Kong and Preah Sihanouk high proportions of raids were on crops that were, overall throughout Cambodia, raided least frequently (Fig. 3). The frequency of crop-raiding events and the amount of damage varied considerably between years, and both frequency and damage were highest in $2005(140$
TABLE 2 Total counts of crops damaged in crop-raiding events, in descending order, from August 2003 to April 2008 inclusive. More than one crop type may be damaged per recorded cropraiding event. Pairwise comparisons are $\mathrm{P}<0.001$ between rice and banana, and banana and cassava, $\mathrm{P}<0.01$ between pineapple and papaya, and $\mathrm{P}<0.05$ between cassava and coconut, sugar cane and mango, coconut and pineapple, jackfruit and lemongrass, and watermelon and cashew.

\begin{tabular}{ll}
\hline & Total count of \\
Crop type & 110 \\
\hline Rice Oryza sativa & 67 \\
Banana Musa spp. & 23 \\
Cassava Manihot esculenta & 15 \\
Sugar cane Saccharum officinarum & 14 \\
Papaya Carica papaya & 11 \\
Coconut Cocos nucifera & 7 \\
Jackfruit Artocarpus heterophyllus & 7 \\
Watermelon Citrillus lanatus & 6 \\
Mango Mangifera indica & 5 \\
Pineapple Ananas comosus & 3 \\
Maize Zea mays & 3 \\
Mixed crop (rice \& maize) & 2 \\
Lemongrass Cymbopogon citratus & 1 \\
Cashew Anacardium occidentale & 1 \\
Chilli Capsicum annumm & 1 \\
Durian Durio spp. & 1 \\
Garlic Allium sativum & 1 \\
Mangosteen Garcinia mangostana & 1 \\
Peanut Arachis hypogaea & 1 \\
Pumpkin Cucurbita spp. & 1 \\
Taro Colocasia esculenta &
\end{tabular}

counts of crop damage in 97 individual crop-raiding events; Fig. 4). The decline in events between 2005 and subsequent years was significant $(z=6.636, \mathrm{P}<0.001)$ and was marked for two provinces: Mondulkiri and Kampong Speu. There were low levels of raiding across all years in Koh Kong. Preah Sihanouk had only one recorded raid in 2004.

The number of raids on different crops varied between years (Friedman $\chi^{2}=10.125, \mathrm{df}=3,5, \mathrm{P}=0.018$ ), although

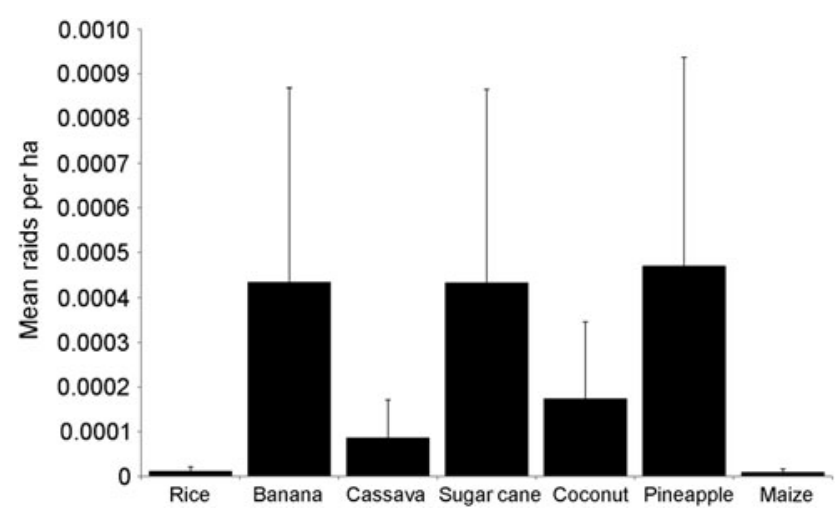

FIG. 2 Mean frequency ( \pm SE) of crop raids per ha cultivated for the seven crop types for which total harvested area was available (FAO, 2009a) for 2004-2007. 


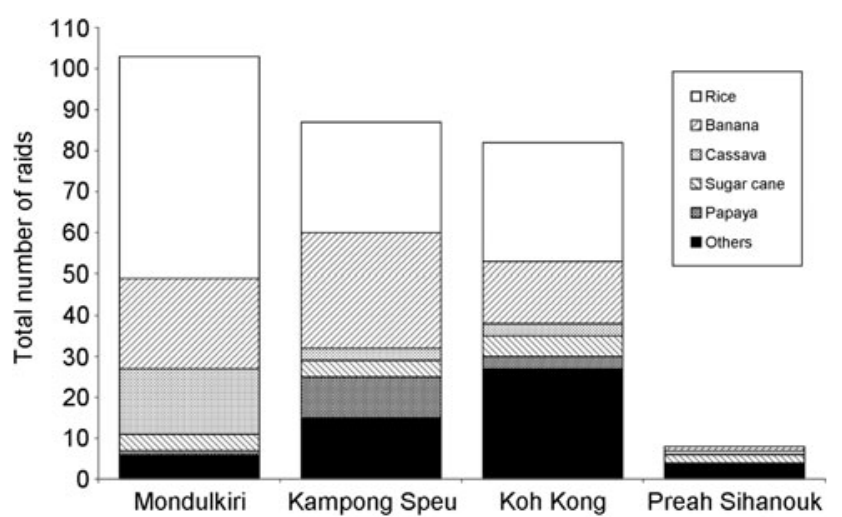

FIG. 3 Total number of raids on each crop type per province from August 2003 to April 2008 inclusive in the provinces of Monduikiri, Kampong Speu, Koh Kong and Phreah Sihanouk (Fig. 1). Crops grouped as others are coconut, jackfruit, watermelon, mango, pineapple, maize, mixed crop (rice and maize), lemongrass, cashew, chilli, durian, garlic, mangosteen, peanut, pumpkin and taro.

the proportions of the crops that were damaged remained relatively constant (Friedman $\chi^{2}=9.161, \mathrm{df}=3,5, \mathrm{P}=0.103$; Fig. 4). Even when raids dropped in frequency the elephants still focused on the same crops overall.

Seasonality, seen in the monthly variation with which crops were raided, was marked (Friedman $\chi^{2}=22.75$, $\mathrm{df}=5,12, \mathrm{P}<0.001)$. There was a peak in crop damage during October-December (Fig. 5a). The lowest frequency of crop damage was from March to June. Monthly variation was a function of planting and harvesting; raiding of rice was significantly positively correlated with rainfall $\left(r_{\mathrm{s}}=0.746, \mathrm{n}=12, \mathrm{P}=0.005\right)$ and there were slight negative associations among some other crops and rainfall (banana $r_{\mathrm{s}}=-0.501, \mathrm{P}=0.097$; papaya $r_{\mathrm{s}}=-0.367, \mathrm{P}>0.5$; other $\left.r_{\mathrm{s}}=-0.231, \mathrm{P}>0.05\right)$. There was also temporal

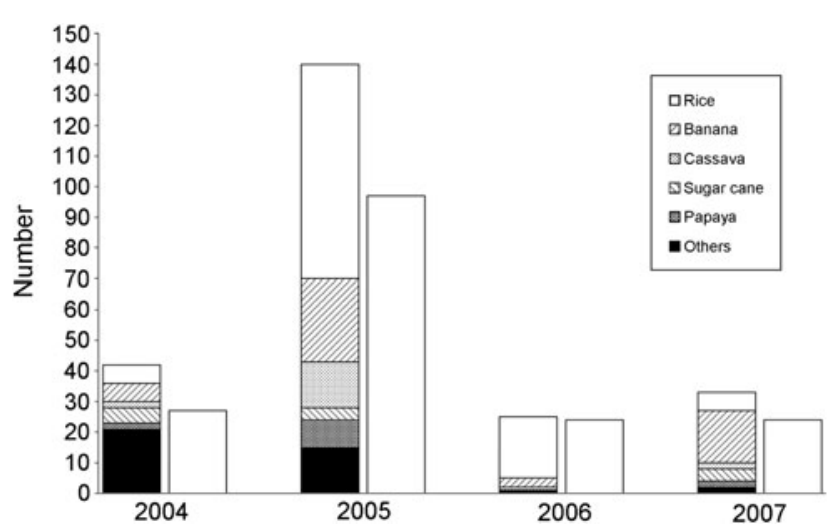

FIG. 4 Total number of crops damaged, on the left, compared to the number of crop-raiding events per year, on the right, from January 2004 to December 2007 inclusive, by year. Crops grouped as others are coconut, jackfruit, watermelon, mango, pineapple, maize, mixed crop (rice and maize), lemongrass, cashew, chilli, durian, garlic, mangosteen, peanut, pumpkin and taro. correspondence among raided crops, with rice and cassava being raided in the same months $\left(r_{\mathrm{s}}=0.746, \mathrm{P}=0.005\right)$, and the frequencies of raids on banana, cassava and others were all correlated (banana and cassava: $r_{\mathrm{s}}=0.581$, $\mathrm{P}=0.048$; banana and others: $r_{\mathrm{s}}=0.757, \mathrm{P}=0.004$; cassava and others: $r_{\mathrm{s}}=0.609, \mathrm{P}=0.036$ ). Cassava may have been trampled as elephants travelled to more attractive crops.

Monthly crop-raiding frequencies differed considerably among provinces $\left(F_{3,48}=9.54, \mathrm{P}<0.001\right)$. Peaks in cropraiding events in October occurred mainly in Koh Kong and in November and December mainly in Mondulkiri (Fig. 5b). Mondulkiri experienced few raids in other months, with no raids recorded in January, February, April or May. The vulnerability of rice during rainy periods was associated with planting and harvesting (Fig. 6). There was a peak in rice damage in November prior to the monsoon season harvest and during the dry season planting. No raids of rice occurred during January-March, during the dry season crop growth and harvest period. The one record outside these growth periods was in mid April 2006, consisting of damage to $6 \mathrm{~m}^{2}$ of $2,400 \mathrm{~m}^{2}$ of seedling rice in Koh Kong.

\section{Discussion}

Understanding temporal patterns and choice in crop raiding provides information on how to manage and mitigate human-elephant conflict. In Cambodia crop raiding occurred in four provinces with known wild elephant populations, Mondulkiri, Kampong Speu, Koh Kong and Preah Sihanouk. Only limited data are available on the size of these populations. Using capture, mark and recapture from a DNA study of dung samples Pollard et al. (2008) estimated a population of 116 in the Siema Biodiversity Conservation Area (now the Seima Protected Forest) in Mondulkiri. Preliminary results from a similar study by CECG in 2008 in the Cardamom Mountains suggest a population there of c. 175. The majority of the samples were from Koh Kong however, with few from Pursat, Kompong Speu or Kompong Chhnang.

Although it remains to be determined whether the provinces with the largest wild populations experience the most raiding, captive elephants also cause occasional crop damage (J. Highwood, pers. comm.). Mahouts leave their elephants chained to a tree to forage in the surrounding area and, once the elephant has eaten the available foliage, it may break the tree or its chains to search for more food, and thus raid cultivated crops. There are 60 captive elephants in the province of Mondulkiri and 24 in Ratanakiri. Mondulkiri had high frequencies of raiding but none was reported from Ratanakiri. The lack of any association between raiding frequency and the numbers of captive elephants suggests that raiding is unlikely to be due to 'problem' captive elephants. 

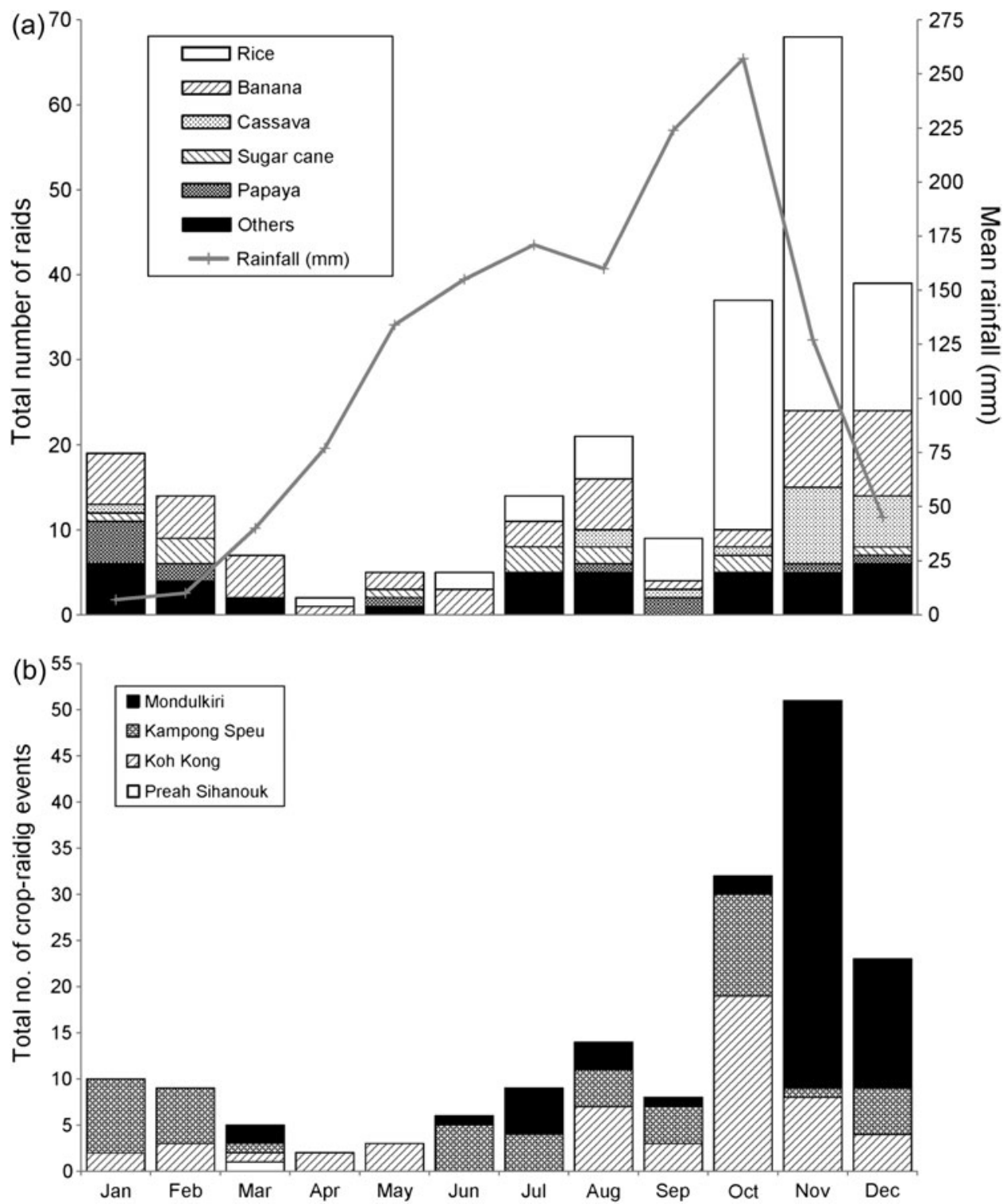

FIG. 5 (a) Total number of crops damaged per month, and mean rainfall per month (mm; for Phnom Penh, from Pearce \& Smith, 1998) from January 2004 to December 2007 inclusive. Crops grouped as others are coconut, jackfruit, watermelon, mango, pineapple, maize, mixed crop (rice and maize), lemongrass, cashew, chilli, durian, garlic, mangosteen, peanut, pumpkin and taro. (b) Total number of crop-raiding events per month in the provinces of Monduikiri, Kampong Speu, Koh Kong and Phreah Sihanouk (Fig. 1) from January 2004 to December 2007 inclusive.

Rice, the country's most important food source for humans, was the most frequently damaged crop and that with the largest area under cultivation (Farquharson et al., 2006). Banana, cassava, sugar cane and papaya were also frequently raided by elephants, and banana, sugar cane and pineapple appeared to be positively selected out of proportion to their availability. Availability was assessed on a national scale, however, and thus does not illustrate local vulnerability. Each crop is unlikely to be available to the elephants for equal periods of time because of variations in lengths of growing periods, which underlie some of the observed annual variation in crop raiding.
Elephants only infrequently raided leafy crops with underground storage organs or less palatable crops such as chilli and garlic. Although elephants may have been targeting underground storage organs in taro, cassava and peanut, there were no records of elephants digging and so they may have been selecting the leaves of these crops. The relative avoidance of some crops could be due to toxicity. Cassava leaves contain cyanotic compounds (Cereda \& Mattos, 1996; USDA NRCS, 2010), taro contains oxalic acid (Savage \& Dubois, 2006) and chilli and garlic volatile irritants (Osborn \& Parker, 2002). Damage to such crops may have been incidental as elephants moved through cultivation to reach 


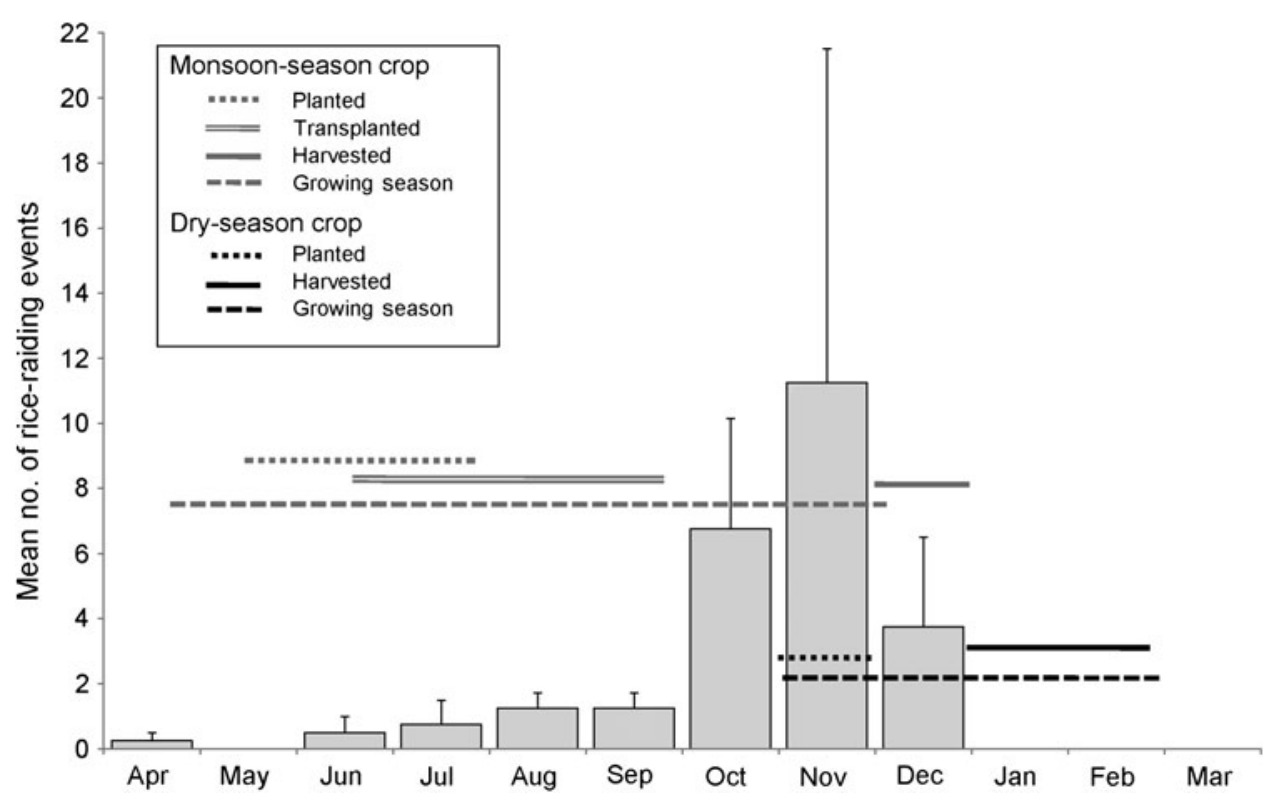

FIG. 6 Rice growth seasons (from Ross, 1987) in Cambodia and mean number of rice-raiding events per month (with SE bars) from January 2004 to December 2007 inclusive.

preferred crops. Unpalatable crops planted in close proximity to preferred crops are unlikely to act as a deterrent when planted on a small scale at the periphery of large fields of highly-preferred crops. Unpalatable crops need to be economically valuable, with a high yield and planted over large areas (Parker \& Osborn, 2006; Hedges \& Gunaryadi, 2010); if such crops could also actively deter elephants, they would have further value (King et al., 2009). Other alternative unpalatable crops include tobacco, tea and, possibly, coffee (Chiyo et al., 2005).

Over the 4 years the same crops were consistently damaged in similar proportions. After the peak of raiding in 2005 there was, however, a decline in the frequency of events associated with the onset of implementation of the CECG's mitigation strategies. The peak of events in 2005 may have been the artificial result of enhanced monitoring, which improved from 2003 onwards. However, our use of an index of events per area harvested suggests that the decline was real, as the index controls for some other sources of variation in raid frequency such as weather, pests and cropping patterns. In addition, after 2005 mitigation was implemented using electric wires, nonlethal explosions and chilli grease. While the relative effectiveness of these tactics has yet to be locally assessed (Hedges \& Gunaryadi, 2010) it was clear that the ability for farmers to plan and implement some form of deterrence was associated with a decline in the frequency of events.

Few crop-raiding events took place in Preah Sihanouk; as an area at low risk of raids it may be better to concentrate mitigation resources in higher risk areas of Kampong Speu, Koh Kong and Mondulkiri. However, the low levels of raids in Preah Sihanouk could be an indication of the efficiency of the small-scale mitigation measures in place there and this possibility needs exploration.

Raids were not evenly distributed across the year; both growth phase and harvest timing will affect the availability of crops for elephants. There was a peak raiding season in October-December, primarily of rice. From January to March rice was not raided, which is surprising as the dry season crops would have been close to maturity. Mapping the locations of major wet and dry season rice crops, as well as other highly selected crops, within provinces could help predict the vulnerability of rice to elephant raids at different times of year, and thus contribute to developing specific deterrents. Resources allocated to mitigation could be usefully concentrated in the peak raiding periods.

In addition to understanding the effects of crop availability, other factors contribute to raiding and these need to be assessed. During the rainy season from April to November forests in Cambodia have adequate forage for elephants (J. Highwood, pers. comm.). A peak of crop-raiding frequency during October-December may be explained by a 'push' factor of a reduction in available wild forage as well as a 'pull' factor of ripening irrigated crops. Osborn (2004) suggested that lower quality and reduced availability of natural forage between the late wet and early dry season encourages raiding. Seasonality in raiding may be associated with the timing of reproductive activities. Most wild Asian bull elephants come into musth during June-December. Although females do not have discrete seasonal periods of oestrus, more come into oestrus in the rainy months of high food availability before vegetation dries out (K.U. Mar, pers. comm.). Prior to musth, males focus on feeding and improving their body condition (Jainudeen et al., 1972; Sukumar, 1989; Mar, 2007). Pre-musth bulls engage in risky 
behaviour such as raiding (Sukumar, 1989). Our study showed an increase in raiding behaviour from October to December, as may be expected if foraging and risk taking were associated with bulls attaining condition to enter musth.

As a result of the evidence and analysis presented here we suggest that determining the relative selection of crops attractive to elephants is critical for designing targeted protection by farming communities. After an elephant crop-raiding incident a list of all crops, including perennial crops or trees, and their maturity and area, in square metres, for raided and neighbouring farms, should be recorded. Records should also include the distance from the raided farm to its nearest neighbouring farm or farms (within a feasible radius). Such information will allow further studies on elephant crop choice. Our study highlights the need for data on which crops are less attractive to elephants and therefore which are associated with reduced crop raiding.

Given a growing human population and an increase in human-dominated landscapes, the natural habitat of elephants is diminishing. The resulting intensification in human-elephant conflict is a major concern for the future of elephants as such conflict can erode local tolerance and lead to retribution killing, potentially resulting in localized extinction of small herds (Heffernan \& Cuong, 2004). If elephants are to survive in Asia it is imperative to investigate humanelephant conflict in detail so as to implement strategies for its alleviation. Continued collection of high-quality crop-raiding data and of other human-elephant interactions by CECG rangers is thus vital for the future of elephants in Cambodia. Long-term strategies for ensuring adequate resourcing of such monitoring projects are urgently required. CECG's work is ongoing and the recommendations and data from this study are being used to help predict and reduce humanelephant conflicts in Cambodia.

\section{Acknowledgements}

The data used for the project were collected by the CECG and the database was constructed by Lo Kimheang of Fauna \& Flora International (FFI). We thank Mao Dawne (CECG Project Assistant) and Lo Kimheang for their help in Cambodia, Gavin Bourchier (Elephant Manager, Compagnie des Eléphants d'Angkor), Khyne U. Mar (Zoological Society of London) and Jack Highwood (Projects Officer, Elephant Livelihood Initiative Environment), the Scottish International Education Trust for financial support to CEW for her MSc, Chester Zoo's Richard Hughes Scholarship and FFI for financial support, and Simon Hedges and two anonymous reviewers for their comments.

\section{References}

BLAKE, S. \& HEDGES, S. (2004) Sinking the flagship: the case of forest elephants in Asia and Africa. Conservation Biology, 18, 1191-1202.
Cereda, M.P. \& Mattos, M.C.Y. (1996) Linamarin: the toxin compound of cassava. Journal of Venomous Animals and Toxins, 2, 1. Doi: 10.1590/So104-79301996000100002.

Chiyo, P.I., Cochrane, E.P., Naughton, L. \& Basuta, G.I. (2005) Temporal patterns of crop raiding by elephants: a response to changes in forage quality or crop availability? African Journal of Ecology, 43, 48-55.

CiA (Central Intelligence Agency) (2008) The World Factbook. Cambodia. Http://www.cia.gov/library/publications/the-worldfactbook/geos/cb.html [accessed 8 August 2008].

Dany, C., Weiler, H., Tong, K. \& Han, S. (2001) The status, distribution and management of the domesticated Asian elephant in Cambodia. In Giants in Our Hands. Proceedings of the International Workshop on the Domesticated Elephant, Bangkok, Thailand, 5-10 February 2001 (eds I. Baker \& M. Kashio), pp. 7988, 111-128. FAO Regional Office for Asia and the Pacific, Bangkok, Thailand.

Duckworth, J.W. \& Hedges, S. (1998) Tracking Tigers: A Review of the Status of Tiger, Asian Elephant, Guar, and Banteng in Vietnam, Lao, Cambodia, and Yunnan (China), with Recommendations for Future Conservation Action. WWF Indochina Programme, Hanoi, Vietnam.

FaO (Food and Agriculture Organization of the United Nations) (2009a) Economics and Social Department: The Statistics Division 2009. Http://faostat.fao.org/site/567/DesktopDefault.aspx? PageID $=567$ \#ancor [accessed 20 April 2009].

FAO (Food and Agriculture Organization of the United Nations) (2009b) State of the World's Forests 2009 (Appendix 2). Forestry Department, Rome, Italy.

Farquharson, R., Sareth, C., Somrangchittra, C., Bell, R.W., VAnG, S., VANCE, W. et al. (2006) Contemporary practices, constraints and opportunities for non-rice crops in Cambodia. Cambodian Journal of Agriculture, 7, 1-12.

Gilmour, D.A., NGuyen, V.S. \& Xiong, T. (2000) Rehabilitation of Degraded Forest Ecosystems in Cambodia, Lao PDR, Thailand and Vietnam. Conservation Issues in Asia. IUCN, Cambridge, UK.

Goldthorpe, G., Heffernan, J. \& Cheang, N. (2003) HumanElephant Conflict Investigation and Recommendations: Busra Commune, Pich Roda District, Mondulkiri. Indochina Elephant Programme, Fauna \& Flora International, Phnom Penh, Cambodia.

Graham, M.D., Douglas-Hamilton, I., Adams, W.M. \& Lee, P.C. (2009) The movement of African elephants in a humandominated land-use mosaic. Animal Conservation, 12, 445-455.

Hedges, S. \& Gunaryadi, D. (2010) Reducing human-elephant conflict: do chillies help deter elephants from entering crop fields? Oryx, 44, 139-146.

Hedges, S., Tyson, M.J., Sitompul, A.F., Kinnaird, M., Gunaryadi, D. \& Aslan (2005) Distribution, status and conservation needs of Asian elephants (Elephas maximus) in Lampung Province, Sumatra, Indonesia. Biological Conservation, $124,35-48$.

Heffernan, P.J. \& Cuong, T.V. (2004) A Review of Conservation Status of the Asian Elephant in Vietnam. Indochina Elephant Programme, Fauna \& Flora International, Cambridge, UK.

HoAre, R. (1999) Determinants of human-elephant conflict in a land-use mosaic. Journal of Applied Ecology, 36, 689-700.

Jainudeen, M.R., McKay, G.M. \& EisenberG, J.F. (1972) Observations on musth in the domesticated Asiatic elephant. Mammalia, 36, 247-261.

Karidozo, M. \& Osborn, F.V. (2005) Can bees deter elephants from raiding crops? An experiment in the communal lands of Zimbabwe. Pachyderm, 39, 26-32. 
Kemf, E. \& Santiapillai, C. (2000) Asian Elephants in the Wild. WWF Species Status Report. WWF-International, Gland, Switzerland.

King, L.E., Lawrence, A., Douglas-Hamilton, I. \& Vollrath, F. (2009) Beehive fence deters crop-raiding elephants. African Journal of Ecology, 47, 131-137.

Leimgruber, P., Gagnon, J.B., Wemmer, C., Kelly, D.S., Songer, M.A. \& SElig, E.R. (2003) Fragmentation of Asia's remaining wildlands: implications for Asian elephant conservation. Animal Conservation, 6, 347-359.

Mar, K.U. (2007) The Demography and Life History of Timber Elephants in Myanmar. PhD thesis, University College London, UK.

Menon, V., Sukumar, R. \& Kumar, A. (1997) A God in Distress: Threats of Poaching and the Ivory Trade to the Asian Elephant in India. Wildlife Protection Society of India, New Delhi, India.

Naughton-Treves, L., Rose, R. \& Treves, A. (1999) The Social Dimensions of Human-Elephant Conflict in Africa: A Literature Review and Case Studies from Uganda and Cameroon. Unpublished Report to the African Elephant Specialist Group, HumanElephant Conflicts Task Force, IUCN, Gland, Switzerland.

O’Connell-Rodwell, C.E., Rodwell, T., Rice, M., \& Hart, L.A. (2000) Living with the modern conservation paradigm: can agricultural communities co-exist with elephants? A five-year case study in East Caprivi, Namibia. Biological Conservation, 93, 381-391.

Osвorn, F.V. (2004) Seasonal variation of feeding patterns and food selection by crop-raiding elephants in Zimbabwe. African Journal of Ecology, 42, 322-327.

Osborn, F.V. \& Parker, G.E. (2002) Living with Elephants II: A Manual. Mid Zambezi Elephant Project, Harare, Zimbabwe.

PARKer, G.E. \& Osborn, F.V. (2006) Investigating the potential for chilli Capsicum spp. to reduce human-wildlife conflict in Zimbabwe. Oryx, 40, 343-346.

Pearce, E.A. \& Smith, C.G. (1993) World Weather Guide. Helicon, Oxford, UK.

Pollard, E., Eggert, L., Chanviboll, C. \& Hedges, S. (2008) The Status and Conservation of Asian Elephants in the Seima Biodiversity Conservation Area, Cambodia. Wilidlife Conservation Society, Phnom Penh, Cambodia.

Remis, M. \& Hardin, R. (2009) Transvalued species in an African forest. Conservation Biology, 23, 1588-1596.

Ross, R.R. (ed.) (1987) Cambodia: A Country Study. GPO for the Library of Congress, Washington, DC, USA. Http://countrystudies.us/cambodia/ [accessed 4 February 2011].

Santiapillai, C. \& Jackson, P. (1990) The Asian Elephant: An Action Plan for its Conservation. IUCN, Gland, Switzerland.

SAVAge, G.P. \& Dubois, M. (2006) The effect of soaking and cooking on the oxalate content of taro leaves. International Journal of Food Sciences \& Nutrition, 57, 376-381.
Sitati, N.W. \& Walpole, M.J. (2006) Assessing farm-based measures for mitigating human-elephant conflict in Transmara District, Kenya. Oryx, 40, 331-336.

Sitati, N.W., Walpole, M.J. \& Leader-Williams, N. (2005) Factors affecting susceptibility of farms to crop raiding by African elephants: using a predictive model to mitigate conflict. Journal of Applied Ecology, 42, 1175-1182.

Suk Umar, R. (1989) The Asian Elephant: Ecology and Management. Cambridge University Press, Cambridge, UK.

SUKUMAR, R. (1990) Ecology of the Asian elephant in southern India II: feeding habits and crop raiding patterns. Journal of Tropical Ecology, 6, 33-53.

Sukumar, R. (2003) The Living Elephants: Evolutionary Ecology, Behaviour, and Conservation. Oxford University Press, Oxford, UK.

SUKUMAR, R. (2006) A brief review of the status, distribution and biology of wild Asian elephants. International Zoo Yearbook, 40, 1-8.

USDA NRCS (United States Department of Agriculture Natural Resources Conservation Service) (2010) Cassava Plant Guide. National Plant Data Center, Baton Rouge, Louisiana and Pacific Islands West Area Office, Mongmong, Guam. Http://plants.usda.gov/plantguide/pdf/cs_maes.pdf [accessed 12 January 2010].

Vance, W.H., Bell, R.W. \& Seng, V. (2004) Rainfall Analysis for the Provinces of Battambang, Kampong, Cham and Takeo, The Kingdom of Cambodia. Unpublished paper. School of Environmental Science, Murdock University, Victoria, Australia.

WildAid Cambodia (2003) WildAid Cambodia, Annual Report 2003. Universal Printing House, Phnom Penh, Cambodia.

\section{Biographical sketches}

C. Elizabeth Webier has research interests in elephant conservation, life histories and behaviour, and particularly in developmental behaviour of wild and captive calves. Tuy Sereivathana has worked with Fauna \& Flora International since 2000, managing elephant conflict work, and is now Project Manager of the Cambodian Elephant Conservation Group. He received the Goldman Environmental Prize in 2010 for his work developing low-cost solutions for mitigation of human-elephant conflict, empowering local communities to participate in elephant conservation. Matthew P. MaLtby is a programme advisor to the Cambodian Elephant Conservation Group and specializes in tropical research expeditions. He has planned and executed large-scale surveys for elusive mammals such as forest elephants and has helped devise new genetic analysis techniques for the monitoring of wildlife populations. PHYLLIS C. LEE's research interests are in human-wildlife interactions and the life histories, longevity, ageing and demography of elephants. 